\title{
Should urinary iodine concentrations of school-aged children continue to be used as proxy for different populations? Analysis of data from Chinese national surveys
}

\author{
Peng Liu ${ }^{1}$, Xiaohui $\mathrm{Su}^{1}, \mathrm{Mu} \mathrm{Li}^{2}$, Hongmei Shen ${ }^{1}$, Jun $\mathrm{Yu}^{1}$, Patrick J. Kelly ${ }^{2}$, Fangang Meng ${ }^{1}$, Lixiang Liu ${ }^{1}$, \\ Lijun Fan $^{1}$, Ming $\mathrm{Li}^{1}$, Shoujun Liu ${ }^{1}{ }^{*}$ and Dianjun Sun ${ }^{1}{ }^{*}$ \\ ${ }^{1}$ Key Lab of Etiology and Epidemiology, Education Bureau of Heilongjiang Province E Ministry of Health, Center for Endemic \\ Disease Control, Chinese Center for Disease Control and Prevention, Harbin Medical University, Harbin 150081, People's \\ Republic of China \\ ${ }^{2}$ Sydney School of Public Health, Sydney Medical School, The University of Sydney, Sydney, 2006, Australia
}

(Submitted 15 May 2016 - Final revision received 20 June 2016 - Accepted 28 June 2016 - First published online 8 August 2016)

\section{Abstract}

I deficiency is a worldwide public health problem. Median urinary I concentration in school-aged children has been used globally as a proxy for all populations. This study aims to determine whether median urinary I concentration of school-aged children is an appropriate indicator of I nutritional status in different adult populations. This is a secondary data analysis of two national I Deficiency Disorder surveys (2011, 2014) and two regional surveys (in coastal areas, 2009, and in high-risk areas, 2009-2014). Population groups included in these surveys were school-aged children (8-10 years), pregnant women, lactating women, women of childbearing age and adults (men and women, 18-45 years). All participants were self-reported healthy without history of thyroid diseases or were not using thyroid medicines. The median urinary I concentration of school-aged children was matched with that of the other population at the county level. The matched populations had similar iodised salt supply, food and water I, food composition and I content in salt. Weak or moderate correlation of median urinary I concentrations was observed between school-aged children and pregnant women and between children and lactating women. However, the agreement was stronger between children and women of childbearing age and between children and adult men and women. The results could be affected by cut-off values, data aggregation level and sample size. Using median urinary I concentration of school-aged children tends to overestimate that of pregnant women and lactating women. Median urinary I concentration of school-aged children can be used for assessing I nutrition in the adult population.

Key words: Median urinary iodine: School-aged children: Pregnant women: Lactating women: Adults

It is estimated that 1.9 billion people are at risk of I deficiency worldwide $^{(1)}$. China is one of the countries most affected by I deficiency disorders (IDD). In 1993, the State Council of China announced a policy to virtually eliminate IDD by year 2000 and adopt universal salt iodisation (USI) as the national strategy ${ }^{(2)}$. Since 1995, China has implemented an I nutrition surveillance system. This system uses the median urinary I concentration (MUI) to monitor I nutritional status in national or regional surveys as recommended by the World Health Organization et $a l^{(3)}$. National IDD survey results indicate that the population's I nutritional status has improved significantly, and China has attained the goal of sustainable IDD elimination since $2005^{(4)}$. In these population-based surveys, school-aged children (SAC, aged 6-12 years) are most commonly involved because of their vulnerability and easy access ${ }^{(3)}$. MUI of SAC has been used as the proxy biological indicator for I nutrition status in the general population for more than two decades under the assumption that it represents the I status of the whole populations ${ }^{(3)}$. Although increasingly surveys measured urinary $\mathrm{I}$ in children, pregnant women or other populations ${ }^{(5-7)}$, a few of them compared the MUI of different populations by geographic area or community levels (national, sub-national, county and household). A number of studies matched the MUI of children only with pregnant women, and the results were inconsistent. Some of them concluded that children's urinary I level could be used as a proxy for pregnant women ${ }^{(8-10)}$; others suggested that MUI of SAC should not be used as a surrogate for monitoring I status during pregnancy ${ }^{(11-13)}$. Evaluation of the

Abbreviations: IDD, iodine deficiency disorders; MUI, median urinary iodine; SAC, school-aged children.

* Corresponding authors: S. Liu, fax +86 4518667 5814, email liusj590406@163.com; D. Sun, fax +864518665 7674, email hrbmusdj@163.com

$\dagger$ Present address: Center for Endemic Disease Control, Chinese Center for Disease Control and Prevention, Harbin Medical University, No. 157 Baojian Road, Nangang District, Harbin, 150081, People's Republic of China. 
current recommendation of using MUI in SAC as a proxy for I status in the general population and population most vulnerable to I deficiency, such as pregnant women, has been recently recognised as a research priority ${ }^{(14)}$. Hence, the aims of this article were to address whether MUI in SAC can be used confidently to indicate I nutritional levels of the following population groups: pregnant women, lactating women, women of childbearing age (non-pregnant and non-lactating) and adult men and women aged 18-45 years and to explore some influencing factors.

\section{Methods \\ Data sources}

This is a secondary data analysis. Fig. 1 describes the flow of data collection, cleaning and analyses; two national and two regional survey data sets were included in this study. In the two most recent (2011 and 2014) National IDD Surveys, the probable proportion to size method ${ }^{(3)}$ was used and stratified at the province level, with thirty counties selected in each province $^{(15)}$. The two regional surveys were the 2009 Iodine Nutrition Survey in Coastal Provinces' Populations (hereafter referred to as the 2009 Coastal Provinces Survey, from north to south, including three provinces, Liaoning, Zhejiang and Fujian, and one municipality, Shanghai, from eleven coastal provinces) ${ }^{(16)}$ and the 2009-2014 High Iodine Deficiency Risk Areas Survey (hereafter referred as High Risk Areas Survey); the counties in this survey were chosen on the basis of historical cretinism prevalence or iodised salt coverage rate lower than $80 \%$. All surveys were approved by the National Health and Family Planning Commission of the People's Republic of China. Informed consent was obtained from all groups of adult participants and from the guardians of SAC. All participants recruited were self-reported healthy and without a history of thyroid diseases or were not taking thyroid medications.

\section{Evaluation standards}

Urinary I concentration of spot urine samples in these surveys was measured using the modified acid digestion method, $\mathrm{As}^{3+}-\mathrm{Ce}^{4+}$ catalytic spectrophotometry ${ }^{(17)}$. The WHO criteria for determining I concentrations were used ${ }^{(1)}$ : for SAC, women of childbearing age and adults, insufficient MUI $<100 \mu \mathrm{g} / \mathrm{l}$, adequate MUI 100-199 $\mu \mathrm{g} / \mathrm{l}$, above requirement MUI 200-299 $\mu \mathrm{g} / \mathrm{l}$ and excessive MUI $\geq 300 \mu \mathrm{g} / \mathrm{l}^{(2)}$; for pregnant women, insufficient MUI $<150 \mu \mathrm{g} / \mathrm{l}$, adequate MUI 150-249 $\mu \mathrm{g} / \mathrm{l}$, above requirement MUI 250-499 $\mu \mathrm{g} / 1$ and excessive MUI $\geq 500 \mu \mathrm{g} / \mathrm{l}$; and for lactating women, insufficient MUI $<100 \mu \mathrm{g} / \mathrm{l}$ (as there is no other cut-off value for above requirement and excess for lactating women, adult cut-off values were used as surrogate in some analyses) ${ }^{(3)}$.

\section{Statistical methods}

The MUI for each population group (SAC, pregnant women, lactating women, women of childbearing age and adults) in each county was calculated. For all surveys, a county's data were excluded from the analysis even one population group's sample size was $<10$. For High Risk Areas Survey, a person's data were excluded from the study if the person had taken iodised oil capsules during the past 12 months before the survey. The data sets from the High Risk Areas Surveys were pooled into 2009-2011 and 2012-2014 sub-data sets as the survey was carried out annually and the population groups were different between two stages. If a county was sampled more than once in different years, then only data from the most recent year were used. The MUI of SAC and MUI of the comparison population groups were matched at county level.

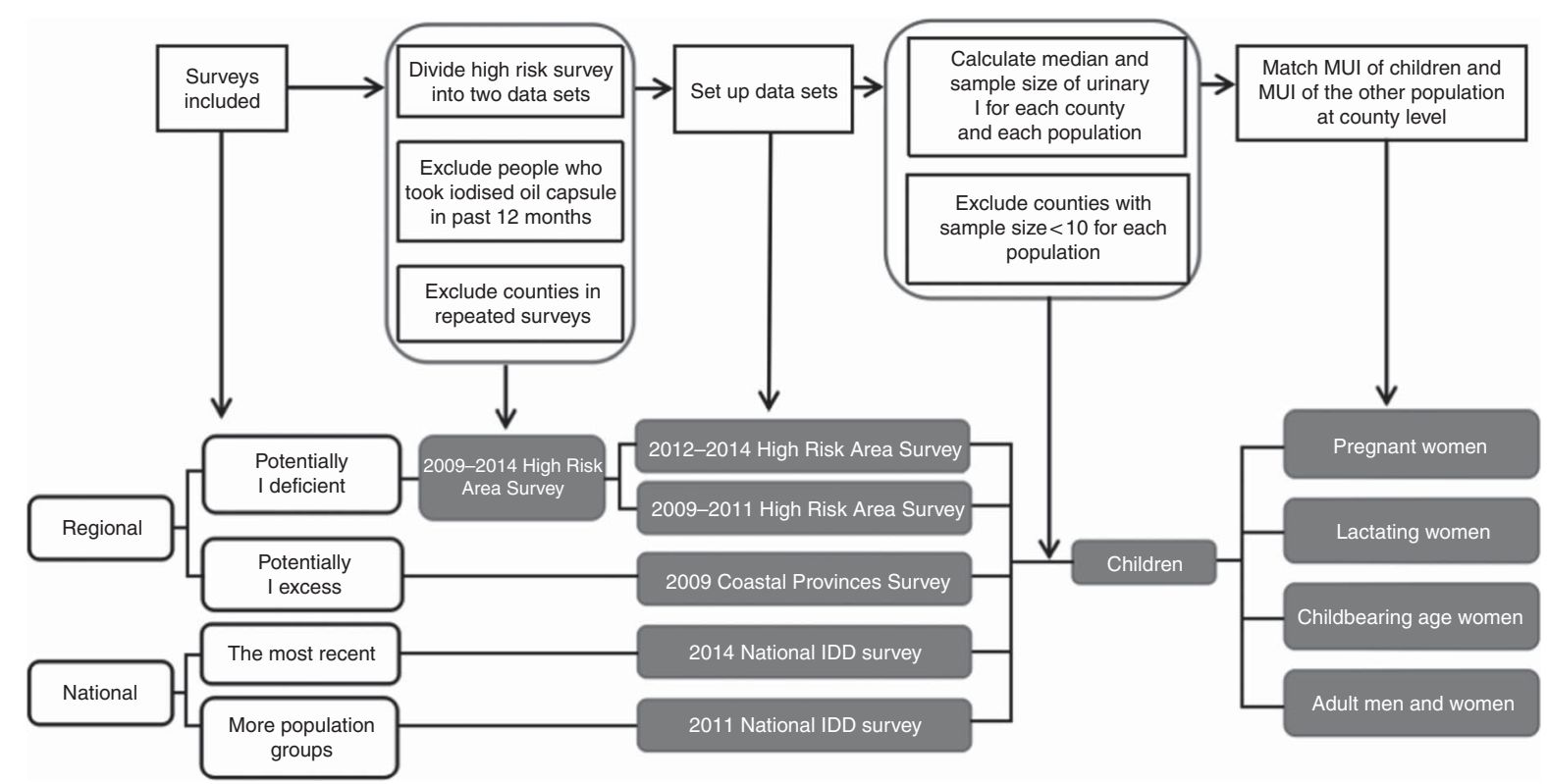

Fig. 1. Flow chart of the data analysed. MUI, median urinary I; IDD, I deficiency disorders. 
In all, three approaches were used to evaluate the correlation and agreement between MUI of SAC and MUI of the other population. First, scatter plots of MUI of the two matched populations were obtained (each dot representing one county, $\mathrm{X}$ axis is the MUI of SAC and $\mathrm{Y}$ axis is the MUI of the other population). Pearson's correlation coefficient was calculated, and values $>0.7$ were defined as high correlation ${ }^{(18)}$. Second, Bland-Altman plots were used to assess agreement (each dot representing one county, $\mathrm{X}$ axis is the mean of MUI of SAC and MUI of the other population for each county and $\mathrm{Y}$ axis is the difference of MUI of SAC and MUI of the other population for each county) ${ }^{(19)}$. For these plots, the mean difference (average of all values in $\mathrm{Y}$ axis) was calculated (with 95\% CI) to assess bias, and agreement limits were calculated using the mean difference \pm 1.96 sD. The better the agreement, the closer the mean difference is to 0 and smaller the range between the two agreement limits. The third approach categorised MUI of each population in all counties into four categories: I insufficient, adequate, above requirement and excessive according to the WHO criteria ${ }^{(3)}$. A two-way table was constructed to compare the SAC and the other population using these categories. The proportion of concordant pairs (the proportion of counties with two matched populations with same I status) and $\kappa$ were then calculated to assess agreement. A $\kappa$ value $>0.4$ indicates a moderate agreement ${ }^{(20)}$.

SPSS 17.0 (Polar Engineering and Consulting) was used for calculating the correlation coefficient, the concordant proportions and for creating the scatter plots, the Bland-Altman plots and the $\kappa$ test.

This study was conducted according to the guidelines laid down in the Declaration of Helsinki, and all surveys were approved by the Harbin Medical University. Written informed consent was obtained from all adult subjects and guardians of children.

\section{Results}

Table 1 summarises the number of samples and counties from each survey that were used for analyses in this study. SAC were included in all surveys, and other populations were included in different surveys; thus, each comparison between two populations may use data sets from different surveys.

\section{Pregnant women and school-aged children}

A total of four data sets were used for comparing MUI concentrations of pregnant women and SAC: the 2011 National IDD Survey (13932 pregnant women and 14975 children), the 2014 National IDD Survey (19500 pregnant women and 48975 children), the 2012-2014 High Risk Areas Survey (2532 pregnant women and 10974 children) and the 2009 Coastal Provinces Survey (1559 pregnant women and 2714 children). The main results are presented in Table 2. Fig. 2 shows the scatter plots constructed with MUI of pregnant women and SAC from the four data sets. In the two national surveys, the Pearson's correlation showed low correlation between MUI of pregnant women and SAC (Fig. 2(a) and (b)). The correlations of the regional surveys were relatively stronger (Fig. 2(c) and (d)).
The mean difference between MUI of pregnant women and SAC was approximately $-50 \mu \mathrm{g} / \mathrm{l}$, which means the MUI of pregnant women was $50 \mu \mathrm{g} / \mathrm{l}$ lower than that of SAC. However, for pregnant women, the value for adequate I nutrition was $150-249 \mu \mathrm{g} / \mathrm{l}$ and it was $100-199 \mu \mathrm{g} / \mathrm{l}$ for children; in other words, in pregnant women, the value should be $50 \mu \mathrm{g} / \mathrm{l}$ higher. The range of agreement limits was wide, nearly $200-400 \mu \mathrm{g} / \mathrm{l}$. The proportion of counties with concordant pairs of pregnant women and SAC classified in the same I nutrition status group was low, only about $30 \%$. The $\kappa$ scores indicated low agreement $(<0 \cdot 1)$.

\section{Lactating women and school-aged children}

We used two data sets for analysing the relationship between lactating women and SAC - the 2011 National IDD Survey (14094 lactating women and 14975 children) and the 2009 Coastal Province Survey (1542 lactating women and 2714 children). Pearson's correlation was low $(r 0 \cdot 18, P<0.05$, Fig. 3(a)) between MUI of lactating women and MUI of SAC in the 2011 National IDD Survey and moderate $(r 0 \cdot 48, P<0 \cdot 05$, Fig. 3(b)) in the 2009 Coastal Provinces Survey. Similar to pregnant women, the Bland-Altman plots showed that the mean difference of MUI in lactating women and SAC was also about $-50 \mu \mathrm{g} / \mathrm{l}$. The range of agreement limits was wide, nearly $200-400 \mu \mathrm{g} / 1$.

The proportion of counties with concordant pairs of MUI of lactating women and SAC classified in the same I status was 36.5 and $59 \cdot 2 \%$, respectively. The $\kappa$ values were also low $(<0 \cdot 2)$.

\section{Women of childbearing age and school-aged children}

The 2009-2011 High Risk Areas Surveys were used to compare MUI between women of childbearing age and SAC (4611 women of childbearing age and 23868 children). A strong correlation was observed between MUI of women of childbearing age and SAC $(r 0.77, P<0.05$, Fig. 3(c)). The Bland-Altman plots showed that the mean difference in MUI between women of childbearing age and SAC was small $(-18.9 \mu \mathrm{g} / \mathrm{l})$, and the range of agreement limits was narrow $(178 \cdot 3 \mu \mathrm{g} / \mathrm{l})$. The proportion of concordant pairs between women of childbearing age and SAC classified within the same MUI category was high (59.3\%, Tables 2 and 3). The agreement was stronger between women of childbearing age and SAC $(\kappa=0.32)$, compared with that between pregnant women and SAC and between lactating women and SAC.

\section{Adult men and women and school-aged children}

The data set from the 2009 Coastal Provinces Survey was used to compare MUI of adult men and women and SAC (1295 adult men and women and 2714 children). Pearson's correlation showed that the relationship between MUI of adults of both sexes and SAC was strong $(r 0.76, P<0.05$, Fig. 3(d)). The Bland-Altman plots showed that the mean difference was close to $0(-4.41 \mu \mathrm{g} / \mathrm{l})$, and the range of agreement limits was narrow $(178.4 \mu \mathrm{g} / \mathrm{l})$. The proportion of concordant pairs classified in the same I level for the two populations was high (69.6\%, Table 3). 


\section{N British Journal of Nutrition}

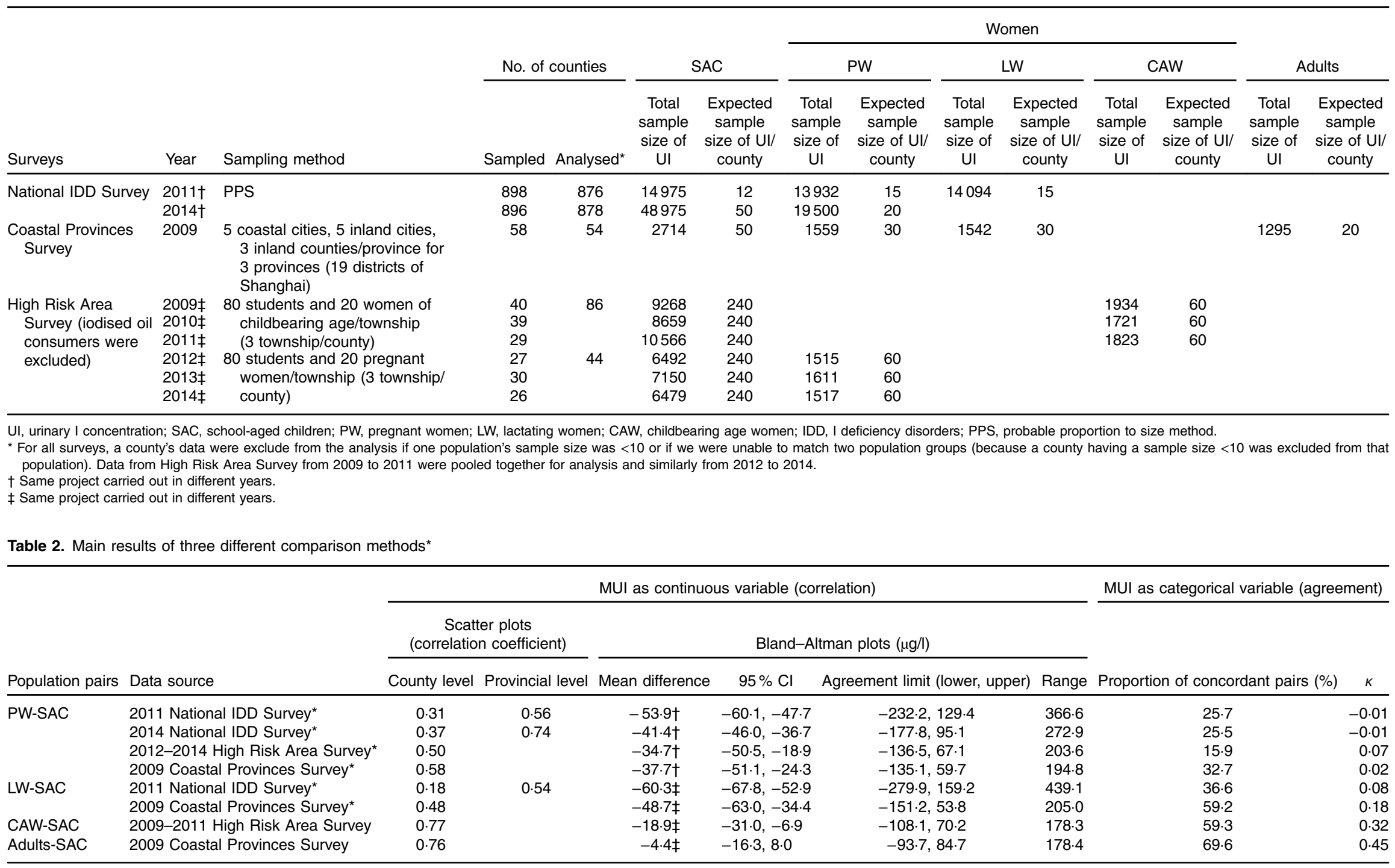

MUI, median urinary I; PW, pregnant women; SAC, school-aged children; LW, lactating women; CAW, childbearing age women

* 'Weak' correlation group for comparing with 'strong' correlation groups.

We expect the mean difference to be $50 \mathrm{\mu g} / \mathrm{s}$ 

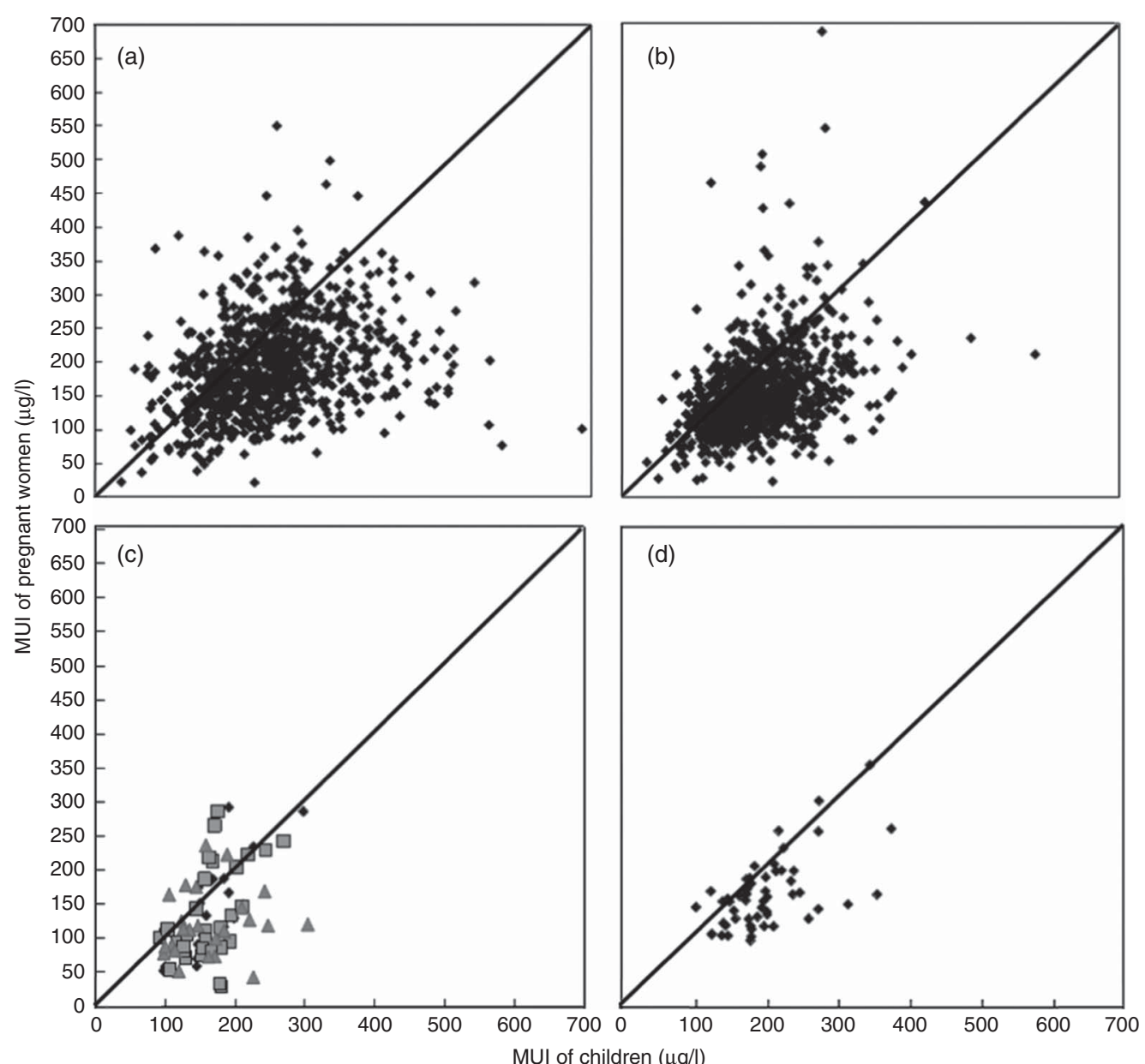

Fig. 2. Scatter plot of median urinary I concentrations (MUI) of pregnant women and children by county level for (a) 2011 National lodine Deficiency Disorder (IDD) Survey ( $n$ 876, $r 0.31, P<0.05$ ), (b) 2014 National IDD Survey $(n 878, r 0.37, P<0.05)$, (c) 2012-2014 High Risk Area Survey $(n 44, r 0.50, P<0.05 ; \diamond, 2012 ; \square, 2013 ; \triangle, 2014)$ and (d) 2009 Coastal Provinces Survey $(n 54, r 0.58, P<0.05)$. Each dot is one county, diagonal lines are $y=x$.

The $\kappa$ value was high $(0 \cdot 45)$, indicating moderate agreement between the adult population and SAC.

\section{Data matched and analysed at the provincial level}

In the above analysis, the MUI of SAC and the MUI of the other population were matched at the county level. In order to determine whether data aggregated at different geographic levels affect the correlation coefficient, data of the two national surveys were also analysed at the provincial level. We found that the correlation coefficient between MUI of pregnant women and MUI of SAC was 0.56 and between MUI of lactating women and MUI of SAC was 0.54 in the 2011 National IDD Survey, and the correlation coefficient was 0.74 between MUI of pregnant women and MUI of SAC in the 2014 National IDD Survey. Both showed improved correlation when data were aggregated at a higher level with larger sample sizes.

\section{Discussion}

In this article, we attempted to answer the question whether MUI of SAC is the most appropriate proxy indicator for measuring I intakes of several adult populations. We used three methods - scatter plots, Bland-Altman plots and proportion of concordant pairs and $\kappa$ and presented consistent results when comparing the 'strong correlation' pairs (women of childbearing age and SAC, adults and SAC) with the 'weak correlation' pairs (pregnant women and SAC, lactating women and SAC) using a correlation coefficient of 0.7 as the cut-off value. Meanwhile, several factors that could possibly affect the correlation or agreement of the results should be considered.

Using the current WHO criteria for assessing I nutrition in SAC and pregnant women, only $13.8 \%$ counties in the 2011 and $19 \cdot 1 \%$ counties in the 2014 National IDD Surveys had MUI of SAC and pregnant women that were within the adequate levels simultaneously. If the 'adequate' I nutrition range for SAC was increased from $100-199 \mu \mathrm{g} / 1$ to $100-299 \mu \mathrm{g} / 1$ as suggested ${ }^{(21)}$, these proportions will increase to 41.2 and $38.9 \%$, respectively (Table 2). Similarly, if the 'adequate' I nutrition range for pregnant women was increased from $150-249$ to $100-249 \mu \mathrm{g} / \mathrm{l}$ as recommended for countries where USI has been effective for at least 2 years with salt adequately iodised and consumed by $>90 \%$ of the population ${ }^{(22)}$, the proportion will be 22.1 and $41.9 \%$, respectively. The third scenario is that if the 'adequate' I nutrition ranges for children and pregnant women were 

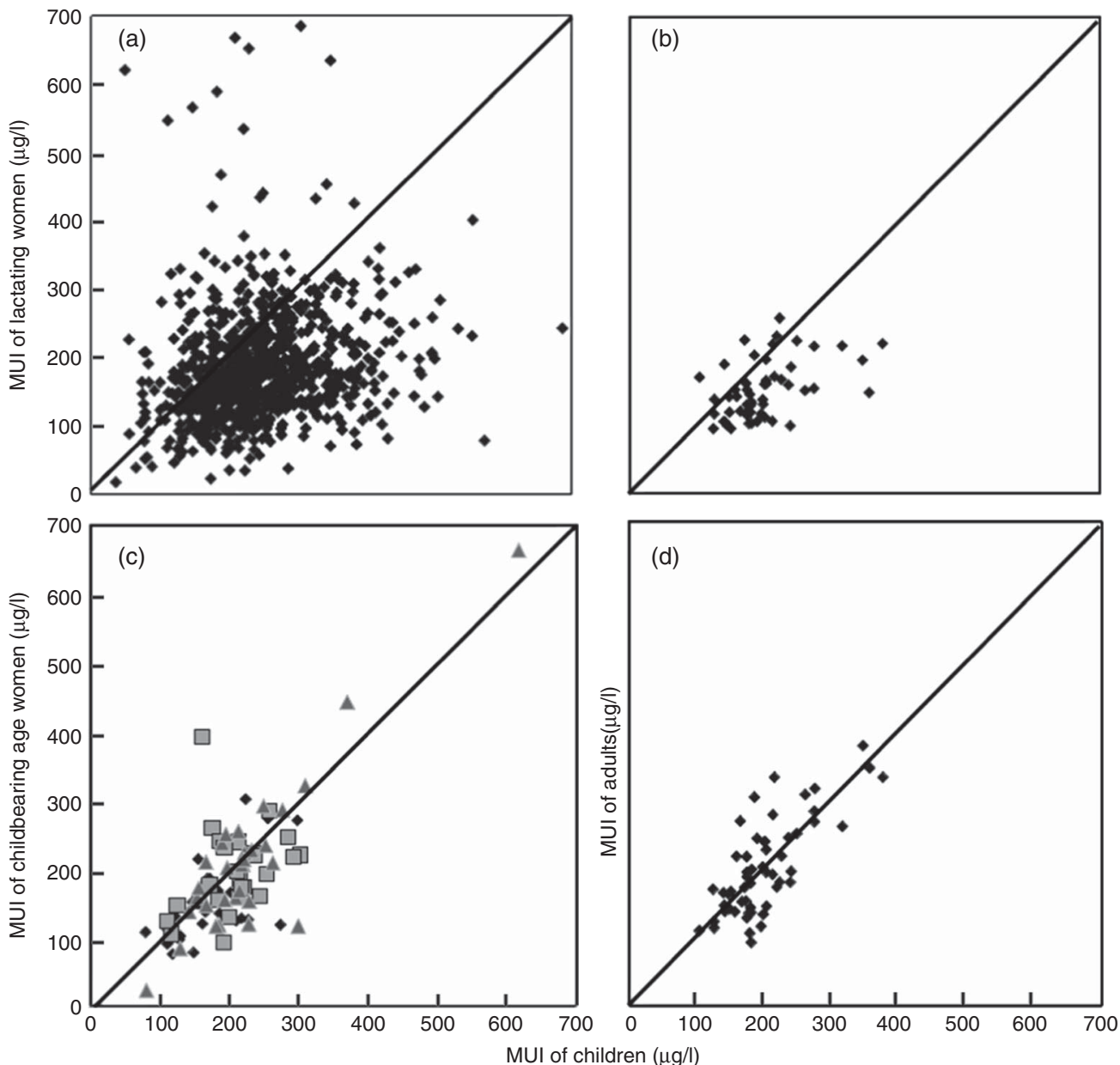

Fig. 3. Scatter plot of county median urinary I concentrations (MUI) between children and (a) lactating women from the 2011 National lodine Deficiency Disorders (IDD) Survey $(n 876, r 0.18, P<0.05)$, (b) lactating women from 2009 Coastal Provinces Survey $(n 54, r 0.48, P<0.05)$, (c) women of childbearing age from 2009-2011 High Risk Area Surveys $(n 86, r 0.77, P<0.05 ;, 2009 ; \square, 2010 ; \triangle, 2011)$ and (d) adults from the 2009 Coastal Provinces Survey $(n 54, r 0.76, P<0.05)$. Each dot is one county, diagonal lines are $y=x$.

increased at the same time (for children, 100-299 $\mu \mathrm{g} / 1$, and for pregnant women, $100-249 \mu \mathrm{g} / \mathrm{l})$, the proportion will be 57.8 and $74.4 \%$ for the 2011 and the 2014 National IDD Surveys, respectively. Thus, the proportion of concordant pairs is sensitive to the change of cut-off points that were used to define the I status. Determination of I nutritional status of a population is currently performed by measuring UIC in spot samples obtained from SAC, from which a MUI is calculated to define that entire population. The validity of calculations or extrapolations from spot urine to define the severity of I deficiency is questionable. Our viewpoint is that the cut-offs of MUI concentration should be reviewed and modified by international organisations, taking habitual dietary I intake and thyroid function status of the surveyed population into consideration.

Data aggregated at the provincial level, rather than the county level, resulted in higher correlation coefficients in this study, and this could be the result of increased sample size. However, studies have shown different correlation coefficients when data were aggregated at sub-national, community and household levels. For example, two studies by Wong et al. ${ }^{(8)}$ and Yan et al. ${ }^{(9)}$ matched data at the sub-national or provincial level and obtained a higher correlation coefficient, $r>0 \cdot 8$; another study matched the data at the settlement level (similar to the county level in this study), and the correlation coefficient was $0.63^{(10)}$. However, when data were matched at the household level, the reported correlation coefficients were much lower, $0 \cdot 43^{(11)}$ and $0 \cdot 16^{(12)}$. The correlation coefficient of urinary I concentrations between SAC and their mothers of childbearing age was also weak $(r 0.17)^{(23)}$. These studies indicate that the level of data matching is a strong influencing factor, which determines the degree of association by impacting on the correlation coefficient.

Urinary sample size influences the median precision of the estimates ${ }^{(24)}$. The number of urine samples collected from each county was different in 2011 and 2014 National IDD Surveys - they were twelve and fifty for SAC and fifteen and twenty for pregnant women from each sample unit (children from schools and pregnant women from communities surrounding the schools), respectively. When the sample size is close to thirty, the variance of the median will be $20 \%$, and when the sample size is close to fourteen the variance will be $30 \%{ }^{(25)}$. This might be partly reflected in the results, as the 2014 survey had a relatively high correlation coefficient compared with the 2011 survey. 
Table 3. Proportion of concordant and discordant pairs for categorised MUI levels between pregnant women, lactating women, childbearing age women, adults and school-aged children*

\begin{tabular}{|c|c|c|c|c|c|c|c|c|c|c|c|}
\hline \multirow[b]{3}{*}{ Population } & \multirow[b]{3}{*}{ Data source } & \multirow[b]{3}{*}{ Category } & \multirow[b]{3}{*}{ MUI $(\mu \mathrm{g} / \mathrm{l})$} & \multicolumn{8}{|c|}{ MUI of SAC } \\
\hline & & & & \multicolumn{2}{|c|}{ Insufficient $(<100)$} & \multicolumn{2}{|c|}{ Adequate (100-) } & \multicolumn{2}{|c|}{ Above requirement (200-) } & \multicolumn{2}{|c|}{ Excessive (300-) } \\
\hline & & & & $n$ & Counties (\%) & $n$ & Counties (\%) & $n$ & Counties (\%) & $n$ & Counties (\%) \\
\hline \multirow{8}{*}{ PW } & 2011 National IDD Survey & Insufficient & $<150$ & 15 & $1.7^{*}$ & 105 & $12 \cdot 0$ & 88 & $10 \cdot 1$ & 30 & 3.4 \\
\hline & & Adequate & $150-$ & 6 & 0.7 & 121 & $13.8 \dagger$ & 240 & $27 \cdot 4$ & 101 & 11.5 \\
\hline & & Above requirement & $250-$ & 1 & 0.1 & 16 & 1.8 & 89 & $10 \cdot 2 \ddagger$ & 63 & $7 \cdot 2$ \\
\hline & & Excessive & $500-$ & 0 & 0.0 & 0 & 0.0 & 1 & 0.1 & 0 & $0.0 \S$ \\
\hline & 2014 National IDD Survey & Insufficient & $<150$ & 26 & $3.0^{*}$ & 280 & 31.9 & 136 & $15 \cdot 5$ & 11 & 1.3 \\
\hline & & Adequate & $150-$ & 2 & 0.2 & 168 & $19 \cdot 1 \dagger$ & 174 & $19 \cdot 8$ & 30 & 3.4 \\
\hline & & Above requirement & $250-$ & 0 & 0.0 & 12 & 1.4 & 30 & $3.4 \ddagger$ & 6 & 0.7 \\
\hline & & Excessive & $500-$ & 0 & 0.0 & 1 & 0.1 & 2 & 0.2 & 0 & $0.0 \S$ \\
\hline \multirow[t]{4}{*}{ LW } & 2011 National IDD Survey & Insufficient & $<100$ & 8 & $0.9^{\star}$ & 32 & 3.7 & 26 & 3.0 & 8 & 0.9 \\
\hline & & Adequate & $100-$ & 9 & 1.0 & 156 & $17.8 \dagger$ & 233 & $26 \cdot 7$ & 97 & $11 \cdot 1$ \\
\hline & & Above requirement & $200-$ & 3 & 0.3 & 41 & 4.7 & 135 & $15 \cdot 4 \ddagger$ & 68 & 7.8 \\
\hline & & Excessive & $300-$ & 1 & 0.1 & 13 & 1.5 & 22 & 2.5 & 22 & $2.5 \S$ \\
\hline \multirow{4}{*}{ CAW } & 2009-2011 High Risk Areas Surveys & Insufficient & $<100$ & 1 & $1.2^{*}$ & 7 & $8 \cdot 1$ & 0 & 0.0 & 0 & 0.0 \\
\hline & & Adequate & $100-$ & 1 & 1.2 & 27 & $31.4 \dagger$ & 17 & $19 \cdot 8$ & 1 & 1.2 \\
\hline & & Above requirement & $200-$ & 0 & 0.0 & 7 & $8 \cdot 1$ & 20 & $23 \cdot 3 \ddagger$ & 1 & $1 \cdot 2$ \\
\hline & & Excessive & $300-$ & 0 & 0.0 & 1 & $1 \cdot 2$ & 0 & 0.0 & 3 & $3.5 \S$ \\
\hline \multirow[t]{4}{*}{ Adults } & 2009 Coastal Province Survey & Insufficient & $<100$ & 0 & $0.0^{*}$ & 1 & 1.8 & 0 & 0.0 & 0 & 0.0 \\
\hline & & Adequate & $100-$ & 0 & 0.0 & 27 & $48 \cdot 2 \dagger$ & 7 & $12 \cdot 5$ & 0 & 0.0 \\
\hline & & Above requirement & $200-$ & 0 & 0.0 & 4 & $7 \cdot 1$ & 9 & $16 \cdot 1 \ddagger$ & 1 & $1 \cdot 8$ \\
\hline & & Excessive & $300-$ & 0 & 0.0 & 1 & 1.8 & 3 & 5.4 & 3 & $5.4 \S$ \\
\hline
\end{tabular}

MUI, median of urinary iodine; SAC, school-aged children; IDD, I deficiency disorders; PW, pregnant women; LW, lactating women; CAW, childbearing age women.

* Concordant pairs.

$\ddagger$ Concordant pairs.

$\S$ Concordant pairs. 
The environmental I background (iodised salt supply, food and water I level and food component) among these surveys may vary. For example, the 2009 Coastal Provinces Survey was targeted at coastal regions as it was thought that people in those areas might consume more sea foods, and therefore their I intakes could potentially be high, whereas the 2009-2014 High Risk Area Surveys were focused on regions where people's I intake could potentially be low because of relatively low iodised salt coverage rates. Counties from the sub-national survey are more homogeneous regarding iodised salt supply, food and water I level, food compositions and dietary habits, etc. compared with counties included in the national survey. Furthermore, between 2000 and 2012, the Chinese salt I fortification standard was 35 (sD 15) $\mathrm{mg} / \mathrm{kg}$ across the whole nation. However, in 2012, the new salt iodisation standards were released. Provinces now have the autonomy to choose from one of the three salt iodisation standards 20,25 or $30 \mathrm{mg} / \mathrm{kg} \pm 30 \%{ }^{(26)}$. Despite these variations, in this study, populations were matched at the county level, and all adult population groups were recruited from the same community from where SAC were selected. This means that the two matched population groups are likely to have similar environmental I background and exposure to similar I content in table salt.

In summary, the level of the correlation and agreement between MUI of children and other adult populations might be influenced by factors such as the cut-off values used for the determination of I adequacy, the level of data aggregation and the sample size from each county, while environmental I background and I content in salt may not.

The main strength of this study is that we included data sets from the most recent 2011 and 2014 Chinese National IDD Surveys, as well as two other sub-national surveys, for determining the correlation and agreement of MUI concentrations between SAC and several adult population groups. Inclusion of a mix of different types of surveys also enabled us to explore possible factors that influence whether surveys of SAC are appropriate indicators to monitor the I status of the entire population. We examined MUI as a continuous variable as well as a categorical variable by comparing populations according to the WHO I nutrition status criteria. Furthermore, in this study, we not only compared MUI between SAC and pregnant women, which has attracted a lot of attention in recent years, but also assessed MUI between SAC and lactating women, women of childbearing age and adult men and women, which has rarely been evaluated or reported.

In conclusion, the comprehensive data analysis of several large national and sub-national data sets indicates that the MUI of SAC is not a reliable indicator for representing I nutrition of the most vulnerable populations for I deficiency - namely, pregnant and lactating women. The findings of this study strongly suggest that urinary I concentrations of pregnant women and lactating women and possibly young children should be included in future IDD programme monitoring in addition to SAC.

\section{Acknowledgements}

The authors appreciate all the organisations and people who participated in these surveys, the provincial Centers for Disease Control and Prevention and the Centers for Endemic Disease
Control in thirty-one provinces and Xinjiang construction corps. The authors thank Professor Creswell J. Eastman for his constructive suggestions and comments and Yunfeng Han for his suggestions on statistical methods.

All the surveys were funded by the National Health and Family Planning Commission of China. UNICEF partially contributed to the Coastal Provinces Survey. The funders had no role in the design, analysis or writing of this article.

The author contributions are as follows: X. S., Mu L., H. S., J. Y., S. L. and D. S. designed the research; P. L., F. M., L. L., L. F., Ming L. and P. J. K. collected and analysed the data; P. L. and Mu L. wrote the paper; S. L. and D. S. had primary responsibility for the final content. All the authors read and approved the final version of the manuscript.

The authors have no conflicts of interest to declare.

\section{References}

1. Zimmermann MB \& Andersson M (2012) Update on iodine status worldwide. Curr Opin Endocrinol Diabetes Obes 19, 382-387.

2. Zhao JK \& Haar F (2005) Progress in salt iodization and improved iodine nutrition in China, 1995-99. Food Nutr Bull 25, 337-343

3. World Health Organization, United Nations Children's Fund \& International Council for the control of Iodine Deficiency Disorders (2007) Assessment of Iodine Deficiency Disorders and Monitoring their Elimination. A Guide for Program Managers, 3rd ed. Geneva: WHO.

4. Sun DJ, Xiao DL \& Liu SJ (2014) 2011 Chinese National IDD Survey[M]. Beijing, People's Republic of China: People's Medical Publishing House.

5. Zimmermann MB, Connolly K, Bozo M, et al. (2006) Iodine supplementation improves cognition in iodine-deficient school-children in Albania: a randomized, controlled, double-blind study. Am J Clin Nutr 83, 108-114.

6. Watutantrige FS, Cavedon E, Nacamulli D, et al. (2006) Iodine status from childhood to adulthood in females living in North-East Italy: iodine deficiency is still an issue. Eur J Nutr 55, 335-340.

7. Eric-Alain A, Rajan S, Werner S, et al. (2008) An assessment of progress toward universal salt iodization in Rajasthan, India, using iodine nutrition indicators in school-aged children and pregnant women from the same households. Asia Pac J Clin Nutr 17, 56-62.

8. Wong EM, Sullivan KM, Perrine CG, et al. (2011) Comparison of median urinary iodine concentration as an indicator of iodine status among pregnant women, school-age children, and nonpregnant women. Food Nutr Bull 32, 206-212.

9. Yan YQ, Chen ZP, Yang XM, et al. (2005) Attention to the hiding iodine deficiency in pregnant and lactating women after universal salt iodization: a multi-community study in China. J Endocrino Invest 28, 547-553.

10. Roza BS, Svetlana M \& Frits VDH. (2009) The current salt iodization strategy in Kyrgyzstan ensures sufficient iodine nutrition among school-age children but not pregnant women. Public Health Nutr 13, 623-630.

11. Gowachirapant S, Winichagoon P, Wyss L, et al. (2009) Urinary iodine concentrations indicate iodine deficiency in pregnant Thai women but iodine sufficiency in their school-aged children. J Nutr 139, 1169-1172.

12. Jaiswal N, Melse-Boonstra A, Sharma SK, et al. (2014) The iodized salt programme in Bangalore, India provides adequate iodine intakes in pregnant women and more-than-adequate iodine intakes in their children. Public Health Nutr 18, 403-413. 
13. Ren X, Sang Z, Shen J, et al. (2013) Survey on iodine nutrition in high water regions of children, adult and the third trimester pregnant women in China. Wei Sheng yan jiu (J Hyg Res) 42 , 966-969.

14. Andersson M, de Benoist B \& Rogers L (2010) Epidemiology of iodine deficiency: salt iodisation and iodine status. Best Pract Res Clin Endocrinol Metab 24, 1-11.

15. Liu P, Su XH, Shen HM, et al. (2015) National iodine deficiency disorders: an analysis of surveillance data in 2011. Chin J Endemiol 34, 9-13.

16. Yu J, Liu P, Shen HM, et al. (2011) The inhabitant's iodine nutrition status of some coastal areas in China: a crosssectional study. Chin J Endemiol 30, 594-597.

17. Yan YQ, Zhang YP, Liu LJ, et al. (2006) Method for Determination of Iodine in Urine by $\mathrm{As}^{3+}-\mathrm{Ce}^{4+}$ Catalytic Spectrophotometry (WS/T107-2006). Beijing, People's Republic of China: People's Medical Publishing House.

18. Mukaka MM (2012) Statistics corner: a guide to appropriate use of correlation coefficient in medical research. Malawi Med J 24, 69-71.

19. Rothwell PM (2000) Analysis of agreement between measurements of continuous variables: general principles and lessons from studies of imaging of carotid stenosis. J Neurol 247, 825-834.

20. Landis JR \& Koch GG (1977) The measurement of observer agreement for categorical data. Biometrics 33, 159-174.
21. Zimmermann MB, Aeberli I, Andersson M, et al. (2013) Thyroglobulin is a sensitive measure of both deficient and excess iodine intakes in children and indicates no adverse effects on thyroid function in the UIC range of 100-299 $\mu \mathrm{g} / \mathrm{L}$ : a UNICEF/ICCIDD study group report. J Clin Endocrinol Metab 98, 1271-1280.

22. WHO Secretariat, Andersson M, de Benoist B, et al. (2007) Prevention and control of iodine deficiency in pregnant and lactating women and in children less than 2-years-old: conclusions and recommendations of the Technical Consultation. Public Health Nutr 10, 1606-1611.

23. Vandevijvere S, Mourri AB, Amsalkhir S, et al. (2012) Fortification of bread with iodized salt corrected iodine deficiency in school-aged children, but not in their mothers: a national cross-sectional survey in Belgium. Thyroid 22, 1046-1053.

24. Andersson M, De Benoist B \& Rogers L (2010) Epidemiology of iodine deficiency: salt iodisation and iodine status. Best Pract Res Clin Endocrinol 24, 1-11.

25. Andersen S, Karmisholt J, Pedersen KM, et al. (2008) Reliability of studies of iodine intake and recommendations for number of samples in groups and in individuals. BrJ Nutr 99 , 813-818.

26. Chinese Ministry of Health (2011) Iodine concentration in edible salt. National standard for food safety. GB26878-2011. Distributed on 15 September 2011, implemented on 15 March 2012. 